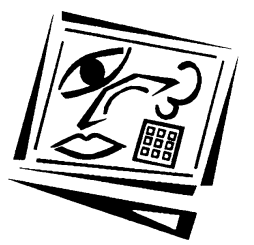

\title{
Peer assisted learning and blogging: A strategy to promote reflective practice during clinical fieldwork
}

\author{
Richard K. Ladyshewsky and Peter Gardner \\ Curtin University of Technology
}

\begin{abstract}
The use of peer assisted learning in clinical education is explored in this case study. Groups of undergraduate physiotherapy students were structured into communities of practice during the second half of their clinical fieldwork program. They collaborated online in an asynchronous manner, using information communications technology (blogs) and focussed their discussion on professional practice and evidence based practice issues. Each blog group was composed of four to five fourth year physiotherapy students in their final year of clinical fieldwork. Each blog group was moderated by an academic moderator. Focus groups were structured to collect information on the experience and outcomes associated with the community of practice experience. The blog was very valuable and heightened learning, built trust, and supported learners to integrate theory to practice. A range of issues were also identified, however, that need to be considered to improve the blogging experience such as increasing the size of the group and providing more detailed guidelines. Clinical fieldwork programs looking to elevate the reflective practice component of professional development should consider blogging as an option.
\end{abstract}

Reflective practice is emerging as an important component of practice in the health professions. Professional associations, regulatory bodies, universities and health care facilities all have a stake in developing the capacity of health professionals. Any strategies that promote this development, therefore, should be welcome (Kaufman, Portney \& Jette, 1997). This paper focuses on the novice practitioner (NP) and efforts to promote reflective practice through the use of blogging, an online technology.

The novice practitioner, in order to develop professionally, must spend a significant amount of time in novel clinical activities and reflect upon these in order to develop a robust clinical knowledge base. This development can be supported by peers who can learn a great deal from one another (Cohen \& Sampson, 1999; Johnson, Johnson \& Smith, 1998; Lake, 1999; Topping, 1996). Learners have reported that they develop many practical skills from their peers even though they had supervisors (Costello, 1989). Given this reality, it is appropriate to consider ways of building this network to assist novices with their reflection and clinical reasoning (Williams, 1995).

There are many forms of clinical reasoning described in the health sciences literature. Earlier research suggested the use of hypothetico-deductive reasoning processes (Elstein, Shulman \& Sprafka, 1978; Grant, Jones \& Maitland, 1988; Umphred, 1995) which involves cue acquisition, hypothesis generation, cue interpretation and hypothesis evaluation. Later research suggests expanded dimensions of clinical reasoning which are distinct from hypothetico-deductive reasoning. These forms of reasoning include: intuitive reasoning (Benner \& Tanner, 1987); narrative reasoning 
(Mattingly, 1991); interactive and conditional reasoning (Fleming, 1991); practical reasoning (Jensen, Gwyer, Hack \& Shepard, 1999); and pragmatic reasoning (Schell \& Cervero, 1993).

These various forms of reasoning do not appear to operate in isolation, but instead, operate in tandem with one another (Edwards, Jones, Jensen, Mayer \& Carr, 2004). For example, during clinical practice, clinicians both 'diagnose' and 'manage' their clients. This is achieved through the application of hypothetico-deductive and narrative reasoning respectively. Alternating through different forms of reasoning during clinical practice is characteristic of the challenges facing the novice practitioner and is referred to as 'dialectical reasoning' (Edwards et al., 2004).

The clinical reasoning of the novice practitioner is quite cumbersome (Oldmeadow, 1996), with errors being common at the early stages of professional development because of the incorrect application and interpretation of biomedical knowledge alongside novel clinical problems (Schmidt \& Boshuizen, 1993). The propensity for the novices to rely on their academic knowledge, and the high incidence of clinical reasoning error, suggests that methods to support reasoning are needed during this stage of professional development.

As noted earlier, peer coaching is one strategy that can be used to support the clinical reasoning of the novice practitioner as it sits well within the framework of experiential learning (Boud \& Edwards, 1999). An experiential learning perspective using learning partnerships results in the integration of biomedical and clinical knowledge from the reflection, discussion and conclusions that take place during the peer coaching dialogue (Carr, Jones \& Higgs, 2000). Researchers support discussion with peers as a strategy for the promotion of clinical reasoning skills (Barker-Schwartz, 1991; Joy Higgs, 1992; Schell \& Cervero, 1993; Terry \& Higgs, 1993) as it brings the learners' thoughts and arguments into the open and allows for discussion and restructuring of knowledge to occur. Discussion about the state of one's knowledge forces novices to explicate their reasoning, which in turn, fosters the development of meta-cognition as it requires students to think about their thinking, and to consider how much they know and do not know.

Meta-cognition is a dimension of clinical reasoning (Higgs \& Titchen, 2000) and leads to deeper learning, as reflection-in-action and reflection-about-action (Schon, 1991) is what leads to clinical expertise (Higgs \& Jones, 2000). Hence, to enhance clinical knowledge, novices needs to reflect upon what they are experiencing in clinical practice and then check whether their understanding matches the concepts of their peers. This concept of discussion and sharing of one's clinical knowledge is a factor in developing clinical expertise. This can be accomplished in part through the act of journal writing. Journal writing helps students understand more deeply their clinical decisions and patient-practitioner interactions and the link to previous learning (Williams, Wessel, Gemus \& Foster-Sargeant, 2002). Williams and Wilkins (1999) also note that journaling helped learners understand the impact of the practice environment on learning and patient care, as well as the acquisition of skills. However, this is a very private activity and may not engender broader discussion and learning unless it is part of a broader reflective process that involves others.

This raises the importance of sharing and discussion of clinical practice issues with others to broaden reasoning and understanding. Such discussion of questions and dilemmas is supported by a range of key philosophers and their social constructivist 
views (Mead, 1934; Wittgenstein, 1953). These authors see the conceptualisation of knowledge as a social artifact that is maintained through a community of peers. For example, Vygotsky determined that social interaction plays a fundamental role in the development of cognition (Vygotsky, 1986). The support of learning from peers in a 'community of practice', as a result, provides opportunities for the novice practitioner to reflect upon propositional knowledge (facts and concepts), professional craft knowledge (learning from experience, skills), and personal knowledge (unique frames of reference and self) (Donaghy, Carey \& Beeman, 1998).

Green (2005) expands upon the work of Vygotsky (1978) using the term 'spaces of influence', where an individual learner can gain learning through the support of others. None of the participants necessarily has the answers, but all are willing to explore spaces that may be unknown to all. This kind of learning experience enables novices to contextualise current knowledge and to acquire skills to deal with situations in the future. Spaces of influence are dynamic in that all participants have a collaborative problem solving role. Reflectivity is central to the space of influence as individuals have time to discover and reflect on information from their own and others' perspectives. Green (2005) has noted five meta-spaces within this space of learning. These are 'spaces of action' where learners take control of their learning, 'spaces of explicit discourse' where learners engage in discourse practices that make critical elements of a learning context clearer, 'spaces of learning' where learners engage with content knowledge relevant to their practice, 'spaces of practice development' where learners share examples of practice and discuss variations of processes, and lastly, 'spaces of trust' where learner's express vulnerability and take risks in learning because of the community of trust.

Peers are also a compelling, yet safe, source for discussions involving clinical practice because they use language and biomedical information which can be easily understand by one another. Further, the communications between peers are less threatening than those that involve supervisors or authorities. Hence, enhanced disclosure, discussion and deeper learning outcomes are possible.

\section{Information and communications technology: Blogging}

Allen (1999) asserted several years ago that the use of the Internet in higher education was not an inert tool and it was reshaping the world of knowledge through its sociotechnological practices. A recent survey (Kim \& Bonk, 2006) emphasises that more blended learning strategies that make use of information and communications technology are on the rise and universities must be responsive to these consumer demands. Most students come to university digitally literate with expectations that universities and resources will be accessible and available and that students can stay connected through technologies such as email, SMS (short message service) and MP3, and hand held devices such as PDAs (personal digital assistants) (Sachs, 2006). As Hilton (2006) notes, students want to be able to use information from others and to use it in novel ways by remodelling, producing and publishing it in different forms. Information and communications technology (ICT) can be used strategically, therefore, to enhance the learners' participation in the intellectual and cultural life of their study (Sachs, 2006), which includes their fieldwork experience.

There is a growing body of literature on the use of web based discussions as a lever for building socially constructed student centred learning (Andrewartha \& Wilmot, 2001; Beerman, 1996; Brennan, McFadden \& Law, 2001; Dunlop \& Scott, 2001; Ellison, 2006; 
Halsne \& Gatta, 2002; Jacobs, 2003; Kim \& Bonk, 2006; McLoughlin, 2000; Mioduser, Nachmias, Lahav \& Oren, 2000; O'Grady, 2001; Ramsay, 2005; Watrall \& Ellison, 2006). Computer based communication is an effective way to increase both social connectivity between learners and collaborative exploration of ideas (Graham \& Scarborough, 1999). Through formulating ideas in their words, and receiving feedback and evaluation from peers, members' knowledge, thinking skills and meanings are socially constructed (Harasim, Hiltz, Teles \& Turoff, 1995).

A recent review of the literature on online teaching and learning reveals that asynchronous communication appears to facilitate in depth communication, suits learners' preferences to move at their own pace, and that learning outcomes appear to be the same as traditional courses. Further, prior training or use of computers increases student satisfaction (Sitzmann, Kraiger, Stewart \& Wisher, 2006). What was particularly interesting from this research was that web based instruction was more effective than class instruction for the learning of declarative knowledge when learners could control their learning over an extended period of time, and when this was combined with actual practice of material with feedback.

The ICT that is used in this research is called a blog. A blog is short for web log (Jacobs, 2003) and is written by individuals or groups of people on the world wide web. It is analogous to an online diary or journal that has open access. A person who writes in a blog is called a blogger. A blog can focus on any topic and is frequently updated in reverse chronological order so the most recent entry appears first. Blogs allow readers to leave written comments as well as links to other websites, photos, and sound files. Blogs are one of the next directions in e-learning and e-education (Ellison, 2006; Mouhtouris, 2006) as they provide creative spaces for learners to co-produce ideas and knowledge (Allen, 1999; Hiler, 2002).

Bruns and Jacobs (2006) note that the use of blogs has proliferated. Individuals through to communities use blogs to communicate with one another and to share ideas. The use of blogs has also continued to grow in political, social and educational circles. However, Bruns and Jacobs (2006) note that there are still inadequate numbers of in depth studies which examine the impact of this technology.

A common educational use of a blog is for students to reflect in writing on their experiences, akin to a learning journal. Ferdig and Trammell (2004) build on the work of Vygotsky (1978) and argue that the discursive nature of knowledge construction is best addressed by the immediacy and contemporary system of blogging. It encourages a natural tendency for reflection and analysis on the part of the student because the feedback system is integral to the blogging interface. It is more successful in creating interactivity that is conversational, active and higher order. Boulos, Maramba and Wheeler (2006) see blogs as offering health science students opportunities for deeper engagement with their clinical learning experiences.

Williams and Jacobs (2004) investigated the use of voluntary blogging in a graduate business program. Forty nine percent of respondents to their survey felt that blogging assisted with their learning, whereas another 23 per cent neither agreed/disagreed. Seventy-seven percent of students felt that the blog increased student interactivity and meaningful intellectual exchange. More than two thirds would have participated in the blog had there not been incentive marks associated with their participation. They concluded that blogging provides a discourse that reaches beyond the scope of a 
university subject and reinforces the fact that students can learn from each other as well as from more formal university resources.

In another study on blogging, Watrall and Ellison (2006) conducted a series of focus groups with students who had experienced blogging as part of their course experience. Benefits included the fact that everyone had a voice in the blog. Students felt they could write more naturally and valued reading the ideas of other peers and accessing new material. They were not concerned about privacy implications given that blogs can be read by anyone. Limitations however, were that it felt like 'busy work' and time constraints sometimes impacted access. Not every single blog entry was of interest, which made commenting back difficult and the number of blog entries was overwhelming in large blog groups.

In terms of learning outcomes Gunawardena, Lowe and Anderson (1998) examined the extent of learning that emerged from computer mediated discussion. Five categories of learning emerged. These were sharing and comparing information; discovering and exploring dissonance and inconsistencies among ideas; negotiating meaning and coconstruction of knowledge; testing and modifying proposed syntheses and coconstructions; and specifying agreement regarding statements and the application of newly constructed meaning.

\section{Research aim and objectives}

An interesting question, therefore, which has driven this exploratory case study is whether blogging, in combination with peer learning strategies can support reflective practice in clinical fieldwork programs. This is similar to what has also been described as a community of practice (Wenger, 1998) in the literature. Blogging may be an excellent resource to support communities of practice. Hence, if there is a positive influence on learning, via blogging, how does this occur and what are the benefits to the learners? The focus of this study, therefore, is to gain a deeper understanding of how blogging supports the reflective practice and learning experience in clinical fieldwork programs.

Specific objectives were to clarify responses to the following three questions:

1. How effective is blogging as a tool to promote reflective practice and learning in a clinical fieldwork program?

2. What were student and academic moderator's perceptions of the experience?

3. What measures need to be put into place to heighten the efficiency and effectiveness of the technology?

\section{Method}

The method used in this research was qualitative with a focus on exploring a particular case. The case study was inclined towards exploring the participants experience with blogging along with the meaning they attached to these experiences. From a philosophical perspective, this aligns somewhat with phenomenology and symbolic interactionism (Denzin \& Lincoln, 2003) where one explores the experiences of individuals and the meanings they attribute to these experiences respectively. Open ended inquiry was preferred as a means of gaining insights into the experiences and meanings of learners and academic moderators. Focus groups were used as data 
collection points (Morgan, 1993). Focus groups are excellent for investigating complex phenomena and for exploring the motivations and meanings that drive behaviour. How individuals interact and the energy created within the group can also be explored through this method. Morgan (1993) asserts that the method allows the investigator to explore consensus and diversity as well as personal views. Weaknesses also exist, however, and this relates to how focussed the group may become in contributing their ideas, and the role of the moderators in collecting and interpreting data.

Thirty-eight undergraduate physiotherapy students were involved in this case study. There were fourteen males and twenty-four females. The mean age of the group was twenty-two years. Six of the eight blog groups were mixed gender with one group comprised of entirely males and one group comprised of entirely females. These students had completed all of their coursework and were in their fourth and final year of their course. The fourth year is comprised of seven full time placements ranging from three to five weeks duration. At the commencement of this project, the students had completed fifty per cent of their fieldwork requirement with fifteen remaining weeks to complete.

Each of the blogging groups was facilitated by an academic moderator. The academic moderators were all faculty of the University and had not experienced blogging before although all were familiar with web based discussion board formats and had facilitated online discussions. It was important to have an academic moderator facilitate the group as this could be used strategically to lever the learners towards deeper learning outcomes, as well as keep learners on track and to ensure confidentiality and ethical etiquette. Research also indicates that learner-instructor involvement increases participants' perceptions of increased learning (Arbaugh \& Benbunan-Fich, 2007).

The students who were part of the blog project were randomly selected from the cohort of fourth year students. Students were either assigned to the 'blogging group' where they wrote their reflective entries within the blog, or in a 'reflective journal group', where they wrote their reflective entries privately in a personal journal. In both cases, students were essentially required to write reflective journal entries, according to preset guidelines, the main difference being the open and collaborative nature of the blog,

Students allocated to the blog group were advised of the nature of the project and requirements. Students were structured randomly into blog subgroups of 5 individuals (in two subgroups there were only four individuals). One individual set up the blog and invited the other four students and the academic moderator to link into the blog. The software tool that was used, blogger.com, allows for private groups with password controlled access. Hence, other students in the class who were outside the specific blog subgroup, did not have access to these blogs. There were eight blog subgroups in total. Students were required to make at least two original blog entries and to make at least four remarks regarding other blog entries for each placement. Students were to blog on the broad topics of professional practice and evidence based practice. Each group was requested to focus their entries on one of the above topics for two placements, and then the other for the subsequent two placements. The students were told that the guidelines did not have to be strictly adhered to and that they were allowed to post entries from the other topic as issues arose in the clinical setting. The guidelines 
applied in this study parallel other programs that have used blogs, for example, 'five meaningful' contributions over six weeks' (Williams \& Jacobs, 2004).

Other reasons for setting up the blog in the manner taken for this study stemmed from other recommendations (O'Grady, 2001). These include having a good reason for the use of ICT, not assuming everyone is familiar with ICT, establishing specific tasks and guidelines for participants to work through, and having academic moderators serve as facilitators to motivate and direct students. This last point is particularly noteworthy. Allen (1999) has noted that these spaces need to de-emphasise the one way flow of information from an 'expert' in favour of facilitated, managed conversations where knowledge is constructed through discussion and exploration.

The program used to blog was Blogger, a free access public blog (https://www.blogger.com/). An external source was used intentionally to provide students with the sense that their blogging was broader than a 'university' experience. It also left students with the opportunity to continue blogging after their formal educational experience, if desired, as it was not linked to university systems and enrolments. Students were provided with a one hour session which reinforced the importance of reflective practice on clinical reasoning as well as provided with an orientation and instruction sheet on how to set up their blog. Guidelines for ethical blog entries were also provided and issues of confidentiality were addressed.

Six weeks into the blog experience a small group met with one of the project team leaders and provided comments on the blog experience to date. The purpose of this formative review was to identify any issues that could be rectified for the remainder of the blogging experience. The eight academic moderators also met with one of the project team leaders and provided comments. Important issues were captured as project notes by the project leader. At the end of the blog project thirty-two of the thirty-eight class members came together and were structured into four interview groups. The two project leaders and two academic moderators facilitated the focus group discussions and collected the feedback. The feedback was collected by the facilitator as written notes which were then reviewed immediately after the session. The written notes were then forwarded to the project leader, who then summarised all the data. The text was then reviewed against the objectives set for this study.

The students were asked a series of set questions modelled on feedback from the first interview group. They were open ended in nature to capture the essence of the participants' learning experience.

The project was part of a curriculum renewal strategy stemming from feedback received from students regarding the poor utility of an end of year written examination to assess clinically based reflective practice. As such, the project was designed to evaluate an alternative method of encouraging and assessing reflective practice. As it is within the scope of the academic program to redesign assessment practices based on student feedback, accreditation requirements, and University teaching and learning plans, no formal consent process was implemented. Reflective practice in clinical education is an accreditation requirement by the professional association. Both student groups completed the same reflective practice requirements. As noted earlier, the only difference was the medium for reflective entries. Nonetheless, the project was put forward to the University's Human Research Ethics Committee and received ethics approval. 


\section{Results}

\section{Academic moderators}

The academic moderators felt that the blog was an improvement over the final clinical written examination held at the end of the academic year. Students were more engaged in discussions about their clinical practice and provided insights into some of the challenges they face during fieldwork. They felt however, that blogging should be introduced earlier into the curriculum. This would enable students to develop their reflective writing and practice skills so that when they entered fourth year they were well prepared, as it was clear some students were more competent at reflection than others.

Moderators also found they had to refrain from taking too 'active' a role as this shifted dependence onto the moderator and reduced the benefits of co-constructive knowledge development amongst peers. In light of this, moderators felt that clearer guidelines would have been useful to help them understand their role more deeply. For example, guidelines encouraging learners to frame their discussions using experiential learning frameworks (eg. describe experience, discuss reflections, summarise conclusions and then consider re-application), and encouraging students to self disclose, be vulnerable, and share issues. Moderators also found that they had to challenge some bloggers to make contributions and to get them to think more laterally. Hence, the moderator took on a 'coaching' or 'facilitator' role versus that of expert, and needed to provide positive reinforcement for high quality entries. This is consistent with the work of Allen (1999) who noted that moderators should facilitate rather than lead discussions in online learning environments.

\section{Student cohort}

Students were asked a range of questions to focus data collection. The results of these responses are reported by the frames of each open ended question addressed in the focus group.

\section{Benefits of blogging}

Students were asked, "What did you like about blogging?"

Students reported that they enjoyed the simplicity, accessibility and convenience of the blogging experience. It could be done wherever there was Internet access and one could go back and edit things as necessary. It did not take a lot of time, it was nonthreatening and did not create the pressure that the examination caused. The pacing of the required work across the semester was beneficial and further reduced assessment pressure and anxiety. It also helped them to consider and practice reflection across the entirety of their fieldwork program. Students reported that it was a more realistic process to use a continual monitoring of their reflective ability. They felt it was a marked improvement over the one off three hour written assessment at the completion of their practical components.

The students also liked the informality of the entry standards as they did not have to comply with conventional academic writing standards. They learned a lot from each other and also gained access to information about other placements. This was particularly helpful for future placement planning and for learning about areas where 
they were not going to have any direct experience. For example, there was one discussion about a patient who had suffered burns and was being treated by one of the physiotherapy students. Students who were going to that placement in future rotations could prepare themselves more readily for the nature of work they were going to face.

The students also appreciated knowing that they were not alone in their struggles, fears and uncertainties. Individuals would write about challenges and doubts that many of them were experiencing and this openness helped to reduce fears and anxieties. They felt that it was useful to share their own experiences with others and to compare these with the experiences of students in similar clinical placements.

You may have doubts about stuff, then realise everyone else has them. You realise you are not alone. You find you did the same thing and you were questioning it, and found they (other students in blog group) did the same thing. It's handy to have that feedback.

The social connection to classmates, especially if alone on a placement, was particularly valuable and reduced the sense of isolation. Students also felt that they could disclose some things that they would not normally discuss with their supervisors, and appreciated the relatively quick feedback. The whole idea of getting peer feedback was a novel concept for some students and they found this very beneficial.

Peer feedback was unique. I never really had peer feedback before, It helped make things more relevant

It was interesting to know what others are thinking ... it opens things up, you know what others are thinking and what they are going through, You feel better if you know others are going through the same thing.

However, the role of the moderator was also important, particularly where a group went off track, or where there were concerns that ideas of the student(s) may be questionable.

I was not sure if ours (group blog) was on track....we needed feedback from the supervisor to get involved and give some more feedback.

The outcomes noted by the students regarding the benefits of blogging align with the concept of a community of practice (Wenger, 1998). Specifically, a social learning process that takes place when individuals, with a common interest or outcome, share their ideas and experiences over time to find new ways of understanding and implementing their practice. Blogging, therefore, can be a useful tool to promote discussion within a select community of practice.

\section{Blogging challenges}

Students were asked, "What did you not like about blogging?"

The typical computing issues emerged such as problems with access, low bandwidth, problems setting up accounts, keyboard literacy, the odd blog entry going missing, misinterpretation of written comments because of a lack of nonverbal cues, and having to learn a new software program.

Two groups had only four members and this turned out to be too small, particularly when one member did not participate fully. This reduced opportunities for social co- 
construction to develop. Another difficulty was that some bloggers only entered their blogs towards the end of their placement, which meant there was a flurry of activity at the end. This again diminished the learning value because there was not enough time to build up a stream of ideas, get feedback and implement suggestions.

Participants also felt some example blogs would have been helpful at the start of the program to get a sense of what is a 'standard' entry. Whilst they liked the informality of the experience, initially they were unsure of how 'academic' the entries needed to be, particularly with respect to writing in third person, referencing, and formatting.

Students felt that the guidelines to follow a particular topic for two placements were limiting and that a more open approach to the topics would be beneficial. Discussions on evidence based practice were also less conducive to reflection as they were rather factual.

(The blog is) supposed to report on evidence based practice but also to reflect as well. This is hard to do the two because it is more like a report on information and less on how you feel and stuff

Professional practice issues were much more conducive to reflection and exploration as clear cut answers were far more ambiguous and uncertain.

Some students commented that they felt that at times the staff moderator posted clinical observations based on their experience too quickly which tended to stifle discussion and peer exploration of ideas. Again this reinforces the notion that moderators should facilitate and not direct discussions (Allen, 1999).

Most students also did not have access to the Internet at their placements because of site restrictions. This meant they had to do their blogging on their own time whereas it could have been beneficial to do this at the placement site if time was available and staff understood why they were sitting at a computer.

The students also would have liked to have read other group's blogs and to make contributions to them as well. While some did, because they got blog addresses from friends, or searched the blog web directory, it appeared that they were reluctant to do this as it was not within the framework of the guidelines. The fact that the blog was open access caused some withholding of information on the part of students because people could identify parties or institutions if the discussion went any deeper. Similarly, some supervisors in the placements were also blog moderators so again, some students felt stifled about what they could write because individuals and agencies could still be identified.

There are some things you couldn't talk about because it would sort of breach confidentiality because they could identify - a supervisor or student.

\section{Enhancing the blogging experience}

Students were asked, "What would you change about the blogging process?"

Students suggested that blogging be introduced earlier into the curriculum and to perhaps have a workshop at University in the computer laboratories where the blogs and accounts could actually be set up. Participants could then experiment and practise using the blogs before departing for their placements. 
Students also recommended that deadlines and incentives for early posting and penalties for late posting be applied for blog entries, so that they were not left to the last minute, thus reducing the benefit of the experience. Some participants would have also preferred more open ended blogging so that they could discuss things beyond professional practice and evidence based practice topics. Another suggestion was to have open blogs which were specifically oriented around a particular professional practice area. For example, have a cardio-respiratory blog and all students on a rotation in that area could read and add comments and ideas to that particular blog.

Student recommended that the blog groups be larger with perhaps 6 to 8 participants to have a wider scope of posts to comment on and to minimise the detrimental effects of having non-participants.

\section{Blogging and reflective practice}

Students were asked, "How did blogging help you in your clinical placement? How did blogging help your reasoning?"

For some students, some of the blogs did not have relevance, whereas others were very useful and provided very good information either currently or in the future. For example, there was one blog on managing group classes and how to work with individuals at different ability levels which bloggers found very helpful. For other students, having already completed a rotation in a clinical area, they could coach and provide support to their peers who were now having a placement in that clinical area.

... some of my pals were treating patients I treated earlier so I could support them ... I could recognise the client they were discussing in the room.

The blog also required students to reflect on their practice which they found beneficial as it "forced you to reflect... you had to make time to stop and think". The input from peers, as well as the academic moderator, also expanded the network of people the blogger could gain assistance from, although sometimes, if you needed some help quickly you didn't get the turn around time needed. It also seemed to take time to get the blogging groups to a level where contributions were more robust.

Only later in the semester were there some good conversations, but early on they were not so great. People didn't have the hang of it, It took some time to get the hang of it all.

Students felt that it gave them an opportunity to process their thoughts and structure them in a more useful manner in writing them down, knowing that they were going to be read by four or five others.

The blog was a non-threatening and safe space where the students could ask, 'stupid' questions.

You can ask (questions) without pressure, and get some feedback and its okay if their stupid (questions).

It was hoped that having the blog external to the University and its technology infrastructure would facilitate this sense of safety or neutrality, and therefore, encourage more self disclosure. The neutrality or non-evaluative status of the blog group provided another option for discussion. The exposure to different clinical areas was also highlighted as a positive feature, as noted in the 'burns placement' example 
earlier. However students highlighted the fact that there was a delay in the responses within the blog group, which was less useful in situations where a more immediate response was needed.

\section{Group cohesion and trust}

Students were asked: "Given other resources such as supervisors, other clinicians, how helpful was blogging? How did you feel about blogging in a group? How did you feel about disclosing aspects of your clinical practice within the group? Please make comments related to trust and your experience in the blog? How did you and your group establish trust?"

Participants stated they were able to build trust in the group although there were still students who would avoid making 'deep' comments and kept things very superficial.

Blogging is not as personal as personal journal so you could put more sensitive and personal stuff in your own journal - you tended to focus on more professional vs. personal stuff.

A few students felt that they had developed trust with each other throughout the course and that this naturally flowed into the group from the start. However, most students acknowledged that trust took some time to develop in the blog group. This is consistent with group theory development and stages of growth. Tuckman (1965) for example notes that groups go through a range of stages before achieving high performance status. There was a sense that everyone was in the same boat so it was easy to share, although there was some apprehension in the early stages of the blog about how much do you self disclose. As one person expanded the scope of their self disclosure, this encouraged others to self disclose more readily.

(I thought) what will the supervisor think, what will other students think ... once you see everyone else is opening up didn't get so stressed.

This movement into a more 'open window' from a 'private window' is a natural progression once trust emerges in a group (Luft \& Ingham, 1955).

Some students highlighted that it was hard to share aspects of clinical practice where they had experienced difficulties and that they felt they needed to be careful in how they worded their posts as they felt the need to continue to present a positive image of their clinical practice. Having an academic moderator observing also influenced entries as "having a supervisor at university was an issue... you're not going to disclose everything".

Some students elected to set up their name for the blog as a nickname. This caused some uncertainty at the beginning because the bloggers were unsure of which class mates were behind the nickname. They would have liked to have known who was in their group from the start, as this made building trust and considering feedback easier. Lastly the importance of acknowledging each other for their contributions was also an important aspect of building the blog community.

\section{Discussion}

The positive benefits gained from this blog experience demonstrate that ICT, in combination with peer coaching, can build the capacity of the novice professional. 
While this study focussed on the novice practitioner, the authors see applications for postgraduate specialisation, rural and remote practitioners and the everyday clinician. It is also not limited to the health sciences sector. Any discipline that has fieldwork could benefit from the use of blogs. For example, preservice teachers that undergo teaching practicums in schools could be networked via blogs to discuss their experiences as teachers and in implementing curriculum.

The blog experience was able to support students through the range of clinical reasoning approaches, as well as creating opportunities to explore evidence based practices in the clinical setting. Many of the same issues noted by Watrall and Ellison (2006) and Farmer, Yue and Brooks (2008), for example, were echoed in the comments of the students, for example, the neutrality and informality of blogging and the value of learning about how others see the same question. The social constructivist discourse that took place also enhanced students' and academic moderators' understanding of professional practice dilemmas and issues. This is certainly consistent with the evidence supporting learning through computer mediated discussion, particularly when linked to practice and feedback (Sitzmann et al., 2006). The operational aspects of the blog facilitated this discourse and was an effective medium for creating a community of practice among the students and academic moderators (Allen, 1999; Hiler, 2002).

The need for reflection, as part of the experiential learning cycle, and the development of clinical competence was also reinforced by the use of blogs. The five metaspaces noted by Green (2005) were evident with students taking charge of learning issues, exploring critical elements of practice and sharing examples of professional skills. Spaces of trust were also quite resounding, and the value of having a neutral group of individuals, aside from those in authority, was highly valued by the students. The five categories of learning noted by Gunawardena et al (1998) as sharing and comparing information; discovering and exploring dissonance and inconsistencies among ideas; negotiating meaning and co-construction of knowledge; testing and modifying proposed syntheses and co-constructions; and specifying agreement regarding statements and the application of newly constructed meaning were all factors that emerged in the feedback and blogs and serve to support clinical reasoning efforts.

The fact some students were poor at reflection or did not engage as fully as other students should not be taken necessarily as a measure of learning effectiveness, even though some learners were frustrated by some blogger's lack of input into the discussions. Nonnecke (2001) notes that 'lurkers', individuals who read but do not necessarily participate in the online discussion, may still be learning through their passive or vicarious (Bandura, 1997, 1977) participation.

In terms of implementation practicalities, it was clear that students and academic moderators need clear guidelines to support them in the blogging environment to optimise learning outcomes. For moderators, guidelines on how to be a facilitator is important information. For students, example blogs, and deadlines for original and return comments, are necessary as these drive blogging behaviour. Introduction earlier into the curriculum is important to develop competency in using blogs and in reflective writing and practice. Similar issues have been raised in other studies where blogs have been used to promote learning and discourse in higher education (Farmer, Yue \& Brooks, 2008). Group size should be larger than 5 but less than 10 to maximise social constructivist discourse, to compensate for lurkers and those who reflect poorly 
or contribute little, and to keep reading volume to an acceptable load. Clinical facilities should also consider providing students with Internet access while at their facilities to increase the timeliness of reflective writing and group feedback. The idea of having blogs that are designated towards a clinical specialty area was an excellent idea as it focuses issues and feedback within that area. However, the rotation of individuals in and out of the blog could interfere with the space of trust and the concomitant self disclosure that is critical for deep reflection and movement into open windows.

\section{Conclusion}

This exploratory case study suggests that the use of blogs in a group of novice physiotherapy students involved in a fieldwork program assisted learners with reflective practice, clinical reasoning and added value to their learning experience. The use of ICT has perhaps not been considered outside the context of the university because of the limits of learning management system technology and their links to student enrolment systems. However, the free access nature of blogging provided students with extended opportunities to build reflective practice networks of students who are engaged in a diverse and geographically spread clinical education fieldwork program. It can be used to build social constructivist discourse networks that serve to enhance the development of their professional practice and overall competency. Hopefully learners will discover the value of ongoing reflective practice as a critical component of professional development and expertise and embrace the value of ICT in supporting their lifelong learning. In fact, any discipline, where reflective practice is an integral part of professional development may look towards blogging and ICT as a learning tool.

\section{References}

Allen, M. (1999). Don't be a troll! Using the Internet for successful higher education. Paper presented at the Higher Education Conference, Sydney.

Andrewartha, G. \& Wilmot, S. (2001). Can multimedia meet tertiary educational needs better than the conventional lecture? A case study. Australian Journal of Educational Technology, 17(1), 1-20. http: / / www.ascilite.org.au/ajet/ajet17/andrewartha.html

Arbaugh, J. \& Benbunan-Fich, R. (2007). The importance of participant interaction in online environments. Decision Support Systems, 43(3), 853-865.

Bandura, A. (1997). Self-efficacy: The exercise of control. New York: W. H. Freeman and Company.

Bandura, A. (Ed.) (1977). Social learning theory (Vol. 5). Englewood Cliffs, NJ: Prentice-Hall.

Barker-Schwartz, K. (1991). Clinical reasoning and new ideas on intelligence: Implications for teaching and learning. American Journal of Occupational Therapy, 45(11), 1033-1037.

Beerman, K. A. (1996). Computer-based multimedia: New directions in teaching and learning. Journal of Nutrition Education, 15(4), 15-18.

Benner, P. \& Tanner, C. (1987). Clinical judgement: How expert nurses use intuition. American Journal of Nursing, 87, 23-31.

Boud, D. \& Edwards, H. (1999). Learning for practice: Promoting learning in clinical and community settings. In J. Higgs \& H. Edwards (Eds.), Educating beginning practitioners: Challenges for health professional education (pp. 173-179). Oxford: Butterworth-Heinemann.

Boulos, M. N. K., Maramba, I. \& Wheeler, S. (2006). Wikis, blogs and podcasts: A new generation of Web-based tools for virtual collaborative clinical practice and education. BMC Medical Education, 6:41. http: / / www.pubmedcentral.nih.gov/ articlerender.fcgi?artid=1564136 
Brennan, R., McFadden, M. \& Law, E. (2001). Review of research: All that glitters is not gold: online delivery of education and training. Leabrook, South Australia: Australian National Training Authority, NCVER. [verified 10 May 2008] http:/ / pandora.nla.gov.au/pan/33208/ 200302120000/www.ncver.edu.au/research/proj/nr9008.pdf

Bruns, A. \& Jacobs J. (Eds.) (2006). Uses of blogs. Peter Lang, New York.

Carr, J., Jones, M. \& Higgs, J. (2000). Learning reasoning in physiotherapy programs. In J. Higgs \& M. Jones (Eds.), Clinical reasoning in the health professions (2nd ed., pp. 198-204). Oxford, UK: Butterworth Heinemann Ltd.

Cohen, R. \& Sampson, J. (1999). Working together: Students learning collaboratively. In J. Higgs \& H. Edwards (Eds.), Educating beginning practitioners: Challenges for health profession education (pp. 204-211). Oxford: Butterworth-Heinemann.

Costello, J. (1989). Learning from each other: Peer teaching and learning in student nurse training. Nurse Education Today, 9, 203-206.

Denzin, N. \& Lincoln, Y. (Eds.) (2003). Strategies of qualitative research (2nd ed.). London: Sage.

Donaghy, M., Carey, M. \& Beeman, H. (1998). Guided reflection: A framework to facdilitate and assess reflective practice within the discipline of physiotherapy. Physiotherapy Theory and Practice, 6, 3-14.

Dunlop, M. \& Scott, D. (2001). An examination of the impact of aspects of online education delivery on students. [viewed 17 Mar 2003, verified 10 May 2008] http: / / ausweb.scu.edu.au/aw01/papers/refereed/dunlop/paper.html

Edwards, I., Jones, M., Jensen, G., Mayer, A.-B. \& Carr, J. (2004). Research report: Clinical reasoning strategies in physical therapy. Physical Therapy, 84(4), 312-335. [verified 10 May 2008] http: / / arrow.unisa.edu.au:8081/1959.8/26916

Ellison, N. \& Wu, Y. (2006). An empirical test of blogging in the classroom. HigherEdBlogCon. http:/ / www.higheredblogcon.com/index.php/an-empirical-test-of-blogging-in-the-classroom/

Elstein, A., Shulman, L. \& Sprafka, S. (1978). Medical problem solving: An analysis of clinical reasoning. Cambridge, Massachussetts: Harvard University Press.

Farmer, B., Yue, A. \& Brooks, C. (2008). Using blogging for higher order learning in large cohort university teaching: A case study. Australasian Journal of Educational Technology, 24(2), 123136. http: / / www.ascilite.org.au/ajet/ ajet24/ farmer.html

Ferdig, R. \& Trammell, K. (2004). Content delivery in 'Blogosphere'. Technological Horizons in Education Journal, February. http: / / www.thejournal.com/articles/16626

Fleming, M. (1991). The therapist with the three track mind. American Journal of Occupational Therapy, 45, 1007-1014.

Graham, M. \& Scarborough, H. (1999). Computer mediated communication and collaborative learning in an undergraduate distance education environment. Australian Journal of Educational Technology, 15(1), 20-46. http: / / www.ascilite.org.au/ajet/ajet15/graham.html

Grant, R., Jones, M. \& Maitland, G. (1988). Clinical decision making in upper quadrant dysfunction. In R. Grant (Ed.), Physical therapy of the cervical and thoracic spine (pp. 51-80). New York: Churchill Livingstone.

Green, P. (2005). Spaces of influence: A framework for analysis of an individual's contribution within communities of practice. Higher Education Research \& Development, 24(4), 293-307.

Gunawardena, C., Lowe, C. \& Anderson, T. (1998). Transcript analysis of computer-mediated conferences as a tool for testing constructivist and social-constructivist learning theories. Paper presented at Distance Learning '98, 14th Annual Conference on Distance Teaching and Learning, 5-7 August, Madison, Wisconsin. [verified 10 May 2008] http: / / eric.ed.gov:80/ERICWebPortal/ contentdelivery/ servlet/ERICServlet?accno=ED422854

Halsne, A. \& Gatta, L. (2002). Online versus traditionally-delivered instruction: A descriptive study of learner characteristics in a community college setting. Online Journal of Distance 
Learning Administration, 5(1). [viewed 17 Apr 2003, verified 10 May 2008]

http:/ / www.westga.edu/\%7Edistance/ojdla/spring51/halsne51

Harasim, L., Hiltz, S., Teles, L. \& Turoff, M. (1995). Learning networks: A field guide to teaching and learning online. Cambridge: The MIT Press.

Higgs, J. (1992). Developing clinical reasoning competencies. Physiotherapy, 78(8), 575-581.

Higgs, J. \& Jones, M. (2000). Clinical reasoning: An introduction. In J. Higgs \& M. Jones (Eds.), Clinical reasoning in the health professions (2nd ed.). New York: Butterworth-Heinemann.

Higgs, J. \& Titchen, A. (2000). Knowledge and reasoning. In J. Higgs \& M. Jones (Eds.), Clinical reasoning in the health professions (2nd ed., pp. 24-32). New York: Butterworth-Heinemann.

Hiler, J. (2002). Blogs as disruptive tech: How weblogs are flying under the radar of the content management giants. [viewed 30 Oct 2006, verified 10 May 2008] http:/ / www.webcrimson.com/ourstories/blogsdisruptivetech.htm

Hilton, J. (2006). The future of higher education: Sunrise or perfect storm. Educause Review, 41(2), 59-71. http:/ / connect.educause.edu/Library / EDUCAUSE+Review/ TheFutureforHigherEducati/ 40619

Jacobs, J. (2003). Communication over exposure: The rise of blogs as a product of cybervoyeurism. Paper presented at the Australian and New Zealand Communication Association Conference, Brisbane. [verified 10 May 2008] http:/ / www.joannejacobs.net/pubs/2003/ANZCA03jjacobs_full.doc

Jensen, G., Gwyer, J., Hack, L. \& Shepard, K. (1999). Expertise in physical therapy practice. Boston: Butterworth-Heinemann.

Johnson, D., Johnson, R. \& Smith, K. (1998). Cooperative learning returns to college: What evidence is there that it works? Change, 30(4), 27-35. [verified 10 May 2008] http:/ / academicadvising.studentservices.dal.ca/Files/Cooperative\%20Learning.pdf

Kaufman, R., Portney, L. \& Jette, D. (1997). Clinical performance of physical therapy students in traditional and problem based curricula. Journal of Physical Therapy Education, 11(1), 26-31.

Kim, K. \& Bonk, C. (2006). The future of online teaching and learning in higher education: The survey says.... Educause Quarterly, 29(4), 22-30. http:/ / connect.educause.edu/Library / EDUCAUSE+Quarterly/ TheFutureofOnlineTeaching / 40000

Lake, D. (1999). Enhancement of student performance in a gross anatomy course with the use of peer tutoring. Journal of Physical Therapy Education, 13(1), 34-38.

Luft, J. \& Ingham, H. (1955). The Johari Window: A graphic model for interpersonal relations. University of California Western Training Laboratory.

Mattingly, C. (1991). The narrative nature of clinical reasoning. American Journal of Occupational Therapy, 45, 998-1005.

McLoughlin, C. (2000). Beyond the halo effect: Investigating the quality of student learning online. [viewed 12 Apr 2003, not found 10 May 2008] http: / / www.scu.edu.au/schools/sawd/moconf/mocpapers/moc16.pdf

Mead, G. (1934). Mind, self and society from teh standpoint of a social behaviourist. Chicago: University of Chicago Press.

Mioduser, D., Nachmias, R., Lahav, O. \& Oren, A. (2000). Web-based learning environments: Current pedagogical and technolgical state. Journal of Research on Computing in Education, 33(1), 55-76.

Morgan, D. (1993). Successful focus groups: Advancing the state of the art. Thousand Oaks, CA: Sage.

Mouhtouris, A. (2006). All about e-learning with Nigel Paine. Campus Review, 8 March, p. 17.

Nonnecke, B. \& Preece, J. (2001). Why lurkers lurk. Paper presented at the ACMIS Conference, Boston. [verified 10 May 2008] http:/ / www.ifsm.umbc.edu/ preece/Papers/AMCISlurker.01.pdf

O'Grady, G. (2001). Maximising the potential of computer mediated discussion: Guidelines for facilitation. CDTL Brief, 4(4). http:/ / www.cdtl.nus.edu.sg/brief/v4n4/sec3.htm 
Oldmeadow, L. (1996). Developing clinical competence: A mastery pathway. Australian Physiotherapy Journal, 42(1), 37-44.

Ramsay, C. (2005). Narrative from learning in reflection to learning in performance. Management Learning, 36(2), 219-235.

Sachs, J. (2006). Technology as a tool or tyrant: Universities responding to the challenges of learning and teaching in an information rich environment. Paper presented at the Global Summit 2006: Technology Connected Futures, Sydney.

Schell, B. \& Cervero, R. (1993). Clinical reasoning in occupational therapy: An integrative review. American Journal of Occupational Therapy, 47(7), 605-610.

Schmidt, H. \& Boshuizen, H. (1993). On acquiring expertise in medicine. Educational Psychology Review, 5(3), 205-221.

Schon, D. (1991). The reflective practitioner: How professionals think in action. London: Ashgate Publishing Ltd.

Sitzmann, T., Kraiger, K., Stewart, D. \& Wisher, R. (2006). The comparative effectiveness of webbased and classroom instruction: A meta-analysis. Personnel Psychology, 59(3), 623-664.

Terry, W. \& Higgs, J. (1993). Educational programmes to develop clinical reasoning skills. Australian Physiotherapy Journal, 39(1), 47-51.

Topping, K. (1996). The effectiveness of peer tutoring in further and higher education: A typology and review of the literature. Higher Education, 32, 321-345.

Tuckman, B. (1965). Developmental sequences in small groups. Psychological Bulletin, 63(6), 384399.

Umphred, D. (1995). Physical therapy differential diagnosis in the clinical setting. Journal of Physical Therapy Education, 9(2), 39-45.

Vygotsky, L. (1978). Mind in society. Cambridge, MA: M.I.T. Press.

Vygotsky, L. (1986). Thought and language. Cambridge, MA: M.I.T. Press.

Watrall, E. \& Ellison, N. (2006). Blogs for learning: A case study. [viewed 30 Oct 2006] http:/ / www.higheredblogcon.com/teaching/ watrall/blogs-for-learning2/ player.html

Wenger, E. (1998). Communities of practice: Learning, meaning and identity. Cambridge: CUP.

Williams, J. \& Jacobs, J. (2004). Exploring the use of blogs as learning spaces in higher education sector. Australasian Journal of Educational Technology, 20(2), 232-247. http: / / www.ascilite.org.au/ajet/ajet20/ williams.html

Williams, L. (1995). Modified teaching clinic: Peer group supervision in clinical training and professional development. American Journal of Speech-Language Pathology, 4(3), 29-38.

Williams, R., Wessel, J., Gemus, M. \& Foster-Sargeant, E. (2002). Journal writing to promote reflection by physical therapy students during clinical placements. Physiotherapy Theory and Practice, 18, 5-15.

Williams, R. \& Wilkins, S. (1999). The use of reflective summary writing as a method of obtaining student feedback about entering physical therapy practice. Journal of Physical Therapy Education, 13, 28-33.

Wittgenstein, L. (1953). Philosophical investigations. Oxford, UK: Blackwell and Mott.

Associate Professor Richard K. Ladyshewsky Graduate School of Business, Curtin University of Technology, GPO Box U1987, Perth WA 6845, Australia.

Email: rick.ladyshewsky@curtin.edu.au

Mr Peter Gardner, School of Physiotherapy, Curtin University of Technology, GPO Box U1987, Perth WA 6845, Australia. Email: p.gardner@curtin.edu.au 